\title{
The Value of Social Psychology: Working with Local Communities in Santiago de Cuba in 2012
}

\author{
Eddie Fisher (Corresponding Author) \\ Faculty of Social Sciences, Universidad de Oriente \\ Ave. Patricio Lumumba, Altos de Quintero \\ Santiago de Cuba, Cuba 90500 \\ Tel: 53-2263-1860Ｅ-mail: eddie.fisher9@btinternet.com
}

Yorkys Santana Gonzalez

Faculty of Social Sciences, Universidad de Oriente

Ave. Patricio Lumumba, Altos de Quintero

Santiago de Cuba, Cuba 90500

Tel: 53-2263-1860 E-mail: ysan@csh.uo.edu.cu

Yarlenis Lleinis Mestre Malfran

Faculty of Social Sciences, Universidad de Oriente

Ave.Patricio Lumumba, Altos de Quintero

Santiago de Cuba, Cuba 90500

Tel: 53-2263-1860 E-mail: yarlenis@ csh.uo.edu.cu

Damiana Perera Calzadilla

Faculty of Social Sciences, Universidad de Oriente

Ave.Patricio Lumumba, Altos de Quintero

Santiago de Cuba, Cuba 90500

Tel: 53-2263-1860 E-mail: dami@csh.uo.edu.cu 
Received: March 5, 2013 Accepted: March 20, 2013

doi:10.5296/ber.v3i1.3354

URL: http://dx.doi.org/10.5296/ber.v3i1.3354

\begin{abstract}
It is recognized by academics and the community of practice that social psychology plays an important role in the everyday life of people, both at individual and at local community level. Recent social psychological research expresses the need to develop a better understanding of what good and effective social support for people looks like. This research report presents the outcomes of a field study by students from the Psychology Stream of the Faculty of Social Sciences of the Universidad de Oriente in Santiago de Cuba. A combination of literature review, face to face interviews and focus group meetings was applied to complete the research objectives. A number of specific approaches were identified as being most important to help members of local communities in Santiago de Cuba to resolve some of their social problems. The results suggest that members of local communities in Santiago de Cuba would benefit from adopting these approaches so they become more self-sufficient and self-confident in addressing their social issues. The findings also suggest that the management and control of emotions can play a vital role in enhancing creativity in people to find solutions to their social problems within the communities of this research. The results suggest that similar outcomes could be achieved in other communities within Cuba.
\end{abstract}

Keywords: Attitude, Behavior, Social Psychology

\title{
1 Introduction
}

\subsection{Introduction}

The Faculty of Social Sciences at the Universidad de Oriente (UO) has been a centre of excellence for social sciences research for many years. The faculty and its work are well-known and respected throughout Cuba. The $\mathrm{UO}$ wishes to raise its profile and recognition in the area of social sciences and has therefore decided to conduct more research in the form of research programs to achieve wider local and international acclaims for its future work. The UO has gained extensive knowledge over the years in many areas such as social perception and attribution, social influence and the psychology of groups. The University has been considering for quite some time how they can apply this wide array of social psychological theories and research to everyday lives, initially, within the local communities in Santiago de Cuba. It has been difficult to find remedies for individual and societal problems within these communities. It has not always been possible to provide social psychological instruments so that the effectiveness of economic and political endeavors can be increased.

These difficulties have now been overcome through the successful completion of some social psychological research work with some local communities in Santiago de Cuba to improve their everyday lives. It appears that there is a growing need for social sciences to support local communities in Santiago de Cuba on a much wider and more in depth scale. The UO has recognized this opportunity and now wishes to engage proactively in helping communities to 
benefit from the work of the faculty of social sciences. Theory is important but on its own is not as effective as theory and practice put together. It was the purpose of this research to combine theory and practice for the benefit of local communities in Santiago de Cuba. Depending on funds and other resources it is possible that this work will be rolled out in future to other cities and areas in Cuba. Based on the results of this research, similar results can be expected but not guaranteed.

The actual preparatory and field work to improve the lives of local communities has now been completed. Academic staff and students from the University have applied both their theoretical and practical knowledge and applied these in real life situations, working closely with members of some selected local communities in Santiago de Cuba. The UO has made a major contribution to help solve, or at least ameliorate, some social problems within these communities. This new applied research has investigated the causes of social problems and designs. It has implemented practical solutions to address the identified social problems and issues local communities have. Another objective of this research was to increase the levels of pro-social behavior of members of the local communities and measure these a few months after the completion of this research. In this context, pro-social behavior is defined as helping someone without being motivated by professional obligations and that the work is not based on an organization (except charities).

\subsection{The Main Research Questions}

This research also investigated possible interventions deemed necessary to improve some social issues. This research has now been completed and it is necessary to analyze, evaluate and present the outcomes from this research.. The main research questions for this current research are:

1. Does a potential shortcoming exist between theoretical knowledge and the practical applications of this knowledge in areas of social psychology?

2. How can interventions help to strengthen the validity of current theories?

3. What are the pro-social behaviors and attitudes of the local communities and how can these be developed?

4. What are the perceptions of the local community how social psychology can support them and if this can help solve social problems?

\subsection{Literature Review}

Social psychology can be applied in everyday life situations such as in the work place, advertising and health. In this context, social psychology is defined as the discipline within psychology that focuses on how social situations determine human behavior (Hewstone, Stroebe and Jonas, 2008). Social contexts develop whenever two or more individuals come together. As humans are a thoroughly social species, large parts of our lives take place in the company of others. We grow up in families, kindergarten and schools. We play in sport teams, attend committees and form work teams. We communicate face to face or via the telephone, letters or E-mail with family and friends, colleagues and supervisors. Social psychology is 
ubiquitous in our daily lives and this is why social psychology is readily applicable and has been widely applied in the real world. Applying social psychology to some of Cuba's most pressing social problems and phenomena is developing into opportunities for social psychology to make major contributions to improve the daily life of local communities.

Buunk and Van Vugt (2008) are strong advocates of the practical application of social psychology to make contributions to the solution of societal problems. They consider that social psychology is not only a basic social science that studies the nature and determinants of human social behavior. It is also an applied discipline of almost relevance for all kinds of societal problems and issues. Today social psychological theories are frequently used in a range of scientific disciplines such as environment, business, preventative medicine and management science. It is also used in sub-disciplines of psychology such as clinical, health and industrial/organizational psychology. They further consider that social psychological processes should not be studied just in the laboratory but also in a variety of field settings and with other populations than undergraduate students. They have developed a new practical model for applying social psychology to social issues and for developing intervention programs. They refer to it as PATH methodology (Problem, Analysis, Test and Help).

A review of the social psychological literature suggests that when two or more individuals come together, a social context for individuals develops. Social psychology focuses on how social situations, for example, in local communities, determine behavior. It appears that social psychology is everywhere in peoples' daily lives. This explains why it is readily applicable in the 'real' world. Early research conducted by La Piere (1934) suggests that it is not possible to predict future behavior if an individual's attitude is known. It appears that people do not always behave in a way that is true to their beliefs. What people say and what they do may be different. Fishbein and Ajzen (1975) suggest that behavior may be more accurately predicted if people know about a person's intentions with respect to behaving in a particular way. This is the basic idea behind their theory of reasoned action which takes into account normative beliefs about appropriate and inappropriate behavior and attitudes towards the behavior.

Skinner (1974) suggests that it is valuable to identify the conditions that account for a behavior so that it is possible to change the conditions if changes in behavior are desired. The assessment of functions of behavior can yield useful information with respect to intervention strategies that are likely to be effective. He considers that operant conditioning is a process that helps people to deal with new environments. As long as individuals can see the value for them for behaving in certain ways, for example, following changes in the social environment, then it will be possible to change people's behaviors by influencing them to do so.

Kiesler, Collins and Miller (1969) consider, in the early years, that behavior is a function of attitudes, norms, habits and expectancies about reinforcement. Attitudes alone do not predict behavior. Attitudes together with norms and habits do. Reber (1995) considers that behavior is a generic term covering acts, activities, responses, reactions, movements, processes, operations and so on, in short, any measurable response of an organism. There has been a long and agonizing tradition of attempting to put some set of coherent limits on the boundaries of denotation of this term. The problem has been that as the range of phenomena included within 
the domain of psychology has increased, there has been a need to expand the boundaries of what can be legitimately called behavior.

Davenport (1999) suggests that human capital comprises all the intangible assets that people bring to their jobs. It's the currency of work, the specie that workers trade for financial and other rewards. It consists of knowledge (command of a body of facts); skill (facility, developed through practice, with the means of carrying out a task); talent (inborn facility for performing a task) and behavior (observable ways of acting that contribute to accomplishing a task.

Allport (1935) considers that attitudes help people to understand the world around them, protect their self-esteem, help them adjust in a complex world and allow them to express their fundamental values (the things that are important to them). He suggests that people can only have an attitude towards a concept that is understood. This view was validated by Katz (1960) who suggests that people tend to act consistently towards an object, for example, if people show respect towards a person, they also are likely to support/follow this person in areas such as political support, invite to dinner, and so on. Their attitude towards this person is thus associated with other similar related social areas.

Maio and Haddock (2010) suggest that attitudes are important. They influence how we view the world, what we think and what we do. They suggest that differences in valence and strength play an important role in understanding the ways in which attitudes influence how we process information and how we behave. Attitudes can also help us express our values, identify with people we like and protect ourselves from negative feedback. They further consider that knowing the primary function of an attitude is important because attempts at attitude change are more likely to be successful when a persuasive appeal matches the function of the attitude.

Ajzen (2005) investigates, for example, why people say one thing and do another, why they behave inconsistently from one situation to another and how people translate their beliefs and feelings into actions. He examines recent innovations in the assessment of attitudes and personality, the implications of those innovations for prediction of behavior, the difference between spontaneous and reasoned processes, and finally, the most recent research on the relations between intentions and behavior. He considers that how we evaluate others can change rapidly depending on events and as new information becomes available about a person or an issue.

Ivancevich and Matteson (1992) suggest that attitudes are determinants of behavior because they are linked to perception, personality and motivation. An attitude is a mental state of readiness, learned and organized through experience, exerting a specific influence on a person's response to people, objects and situations with which it is related. People have attitudes on numerous topics such as politics and friends. The definition of attitude has certain implications for managers: attitudes are learned, define one's predispositions towards given aspects of the world, provide the emotional basis of one's interpersonal relations and identification with others and are organized and close to the core of personality. The behavioral component of an attitude refers to the tendency of a person to act in a certain way towards someone or something. From a managerial perspective, understanding employee attitudes and 
the cognitions and affect that help shape those attitudes, is important in predicting behavior and in modifying attitudes.

Hodgetts et al. (2010) suggest that social psychology has been around for some time as an applied area of the human sciences that attempts to meet the needs of people in society. Social psychology can also be exciting, particularly when we involve ourselves in the events in the world. Social psychologists have a long history of getting involved in social issues. It appears that social psychology and those contributing to its development can be influenced by, and influence, circumstance. Social psychology is maturing. The discipline is increasingly reaching beyond notions of psychology as science and deeper into the social sciences and humanities. Many social psychologists find themselves working as value-oriented and engaged individuals pursuing socially just outcomes through research and practice.

According to Tajfel (1981) no approach to social psychology is value-free and all approaches reflect aspects of the social, historical and political climate in which they are developed. This is why multiple perspectives are valuable. Hodgetts et al. (2010) consider that an ideal within social psychology is the use of research both to address social issues and to generate broader theoretical understandings of pertinent socioeconomic processes shaping such issues. This approach is often referred to as action research (Lewin, 1946; 1948) and involves a cyclical process of theorizing, planning, conducting, gaining feedback on, implementing, evaluating and revising a research project in dialogue with a range of stakeholders from the beginning to the end of a project. Today, social psychologists focus on both the problems that can haunt human lives and the positive relationships and other resources that enable people to avoid, cope with and overcome such problems.

The outcome of the literature review reveals that there appears to be a strong support from social psychologists for the need to explore human interactions in everyday life much more. It is recognized that theory is necessary to develop, for example, social psychological process models. The greatest contribution to society and local communities is made when these are practically applied in people's everyday life. This research is going to be about teamwork and collaboration across boundaries. Everyday life is paramount for this research as this is where people live their lives and engage with others as a matter of course, often without even thinking about it: people say 'Hello' to the bus driver or smile at the sales assistant in a shop. Everyday life is made up of lives that overlap and can be similar as well as different. Social psychology focuses on individuals and groups in society or local communities, what they have in common and what makes them different and unique. This is particularly relevant for the culturally diverse local communities in Santiago de Cuba where many members of these communities come into regular contact with people from different cultures. The focus of this research will be on everyday life as this can reveal a great deal about the origin and consequences of social differences and how social problems can be understood and addressed from different perspectives.

The Research Methodology is presented next followed by Data Analysis and Representation. The Results are then presented and discussed and finally concluded. 


\section{Methodology}

A team of 18 students from the Psychology Stream of the Faculty of Social Sciences of the UO conducted the field research with local communities in Santiago de Cuba during early summer of 2012 under the supervision of a number of full time academic staff from the Faculty. They were split into individual teams of 5, 5, 4 and 4 members respectively. Two local communities known as 'La Risueña' and 'Los Cocos' were selected to conduct this research. 'La Risueña' has 1582 inhabitants, made up of 955 male and 627 female members and 'Los Cocos' has 60 male and 60 female members. Both communities have large numbers of children which are included in the total number of people shown. Communities are typically made up of people who are in full time employment, students, retired people and a small quantity of people who do not work. The students observed psychological constructs such as attitude, behavior and competence of the members of the local communities in the context of this research as part of their research brief. These are defined as follows:

"Attitude is a mental state of readiness, learned and organized through experience, exerting a specific influence on a person's response to people, objects, and situations with which it is related. Attitudes are determinants of behavior because they are linked to perception, personality and motivation"(Ivancevich and Matteson, 1992).

"Behavior is a generic term covering acts, activities, responses, reactions, movements, processes and operations, in other words, any measurable response of an organism"(Reber, 1995)

"Competence refers to areas of work at which the person is competent, the so-called areas for competence. The dimensions of behavior that underpin a competent performance are referred to as person-related" (Moore, Cheng and Dainty, 2002)

Attitudes, behaviors and competences people can actually observe, alone or with others, and where they can see the effects the applications of these have on other people, must be of greater value than being able to only experience these in the mind (positivist research approach). To fulfill the considered research purposes of this study and to make a valid and reliable contribution to knowledge that is of value to both academics and practitioners, the researchers considered that a constructivist interpretivist approach within a phenomenological research paradigm was appropriate, applicable and defendable for this research study. The research paradigm the researchers adopted for this current research-phenomenology, with a constructivist interpretivist approach, is of great importance to the research methodology employed. This current research is about the practical application of social psychology in local communities in Santiago de Cuba. As such, it is important that members of these communities can experience the application of social psychology themselves to verify their validity and reliability. This approach is most suitable as the results will be a construct of the information collected in these communities, in relation to the interpretations provided by the researchers in relation to the collected data.

The phenomenological paradigm, together with a constructivist interpretivist approach is, in the context of the research methodology, more appropriate to identify what the application of 


\section{Macrothink}

Business and Economic Research

ISSN 2162-4860

2013, Vol. 3, No. 1

social psychology in the communities actually means and does in a practical way and, for example, through the process of triangulation, check their validity and detail the strength of evidence that this is based on. This research is about community social psychology or social psychology applied to problems that are generated within areas of these communities. Fig. 1 is a diagrammatical illustration that shows the interrelations between all involved parties in this research. A qualitative research approach was considered most appropriate for this research.

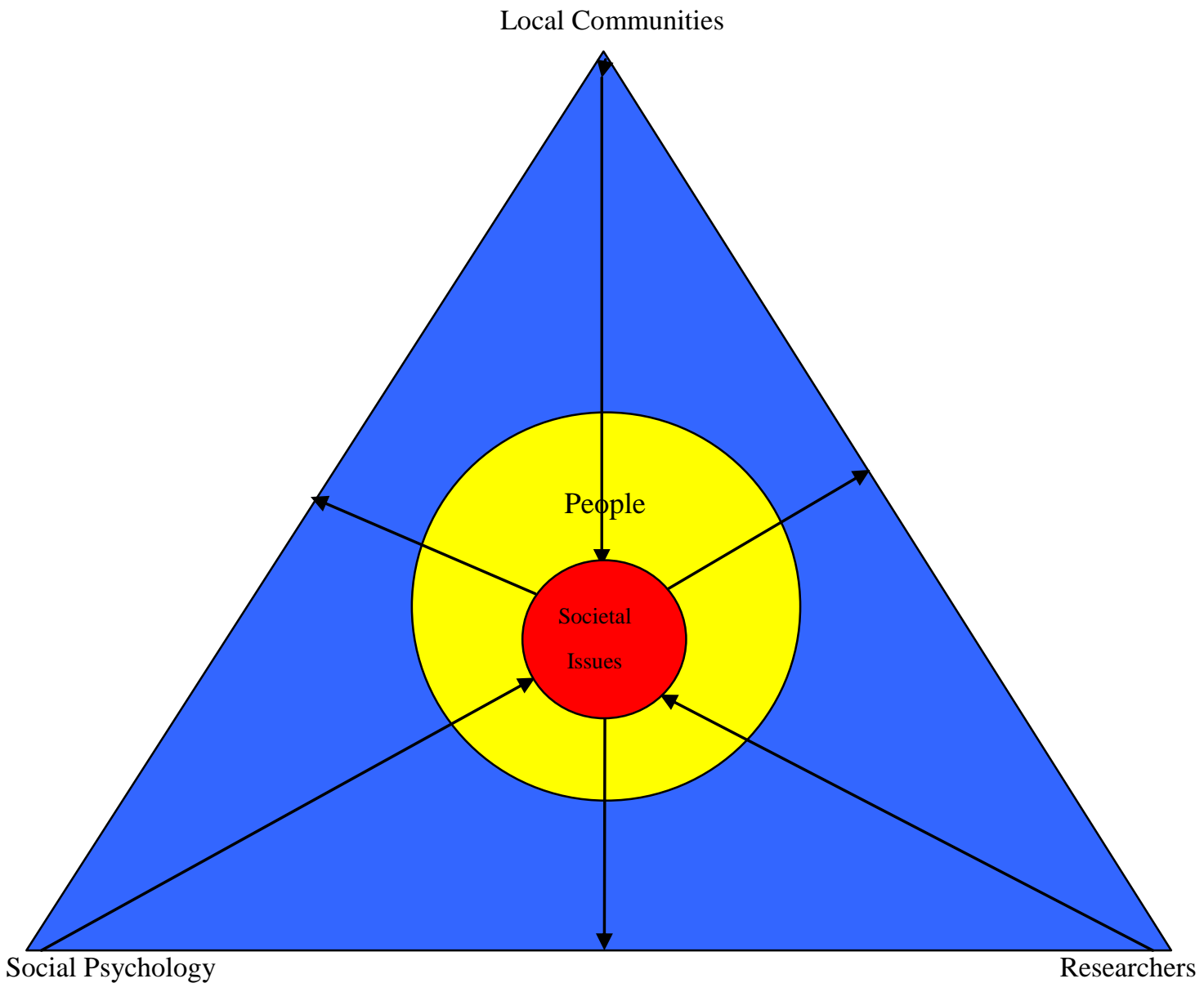

Figure 1. The Theoretical Research Framework

The researchers' focus is on the impact humans make to the activities that are created by social psychology, within this socially constructed world. The researchers epistemological assumption is that reality is subjective and multiple as seen by participants in this study. The contributions from the face to face interviews and any focus group meeting underpin this position. The researchers hold the ontological view, in the context of this research, that the world is socially constructed including social psychology and the people who operate within it, and that this world can only be understood by examining the perceptions of the human actors within it. Fig. 2 is a summary of the research design process.

\begin{tabular}{|c|c|c|c|c|}
\hline Ontology & $\Rightarrow$ Epistemolog & $\Rightarrow$ Methodology & Methods & Sources \\
\hline $\begin{array}{l}\text { What is out there } \\
\text { to know? }\end{array}$ & $\begin{array}{l}\text { What and how } \\
\text { can we know } \\
\text { about it? }\end{array}$ & $\begin{array}{l}\text { How can we go } \\
\text { about acquiring } \\
\text { it? }\end{array}$ & $\begin{array}{l}\text { Which precise } \\
\text { procedure can we } \\
\text { use to acquire it? }\end{array}$ & $\begin{array}{l}\text { Which data can we } \\
\text { collect? }\end{array}$ \\
\hline
\end{tabular}


Figure 2. Research Design and Process

Exploratory interviews (see Appendix $\mathrm{C}$ for details of the interview investigation stages) were conducted to find out how ordinary people think and feel about the topics of concern to the research. This is about ideas collection and not data. These so-called depth interviews required the interviewers to listen almost with a 'third ear' (see Appendix D for details of the qualification criteria for interviewers). These interviews covered a good judgment sample that will be truly representative of the target audience for this research. Interviews will be free style. Interviewers were trained and guided in particular in areas such as active listening, recording of what has been said, ethics, how to manage emotions/feelings (own and audience) and how to display 'respectable social neutrality'.

All research data has been triangulated to ensure the validity and reliability of this research. This includes the outcomes from the literature review, all face to face interviews and the captured information from the focus groups with members of local communities. The data from the research was assessed continuously bearing in mind the following questions as suggested by Bromley (1986):

1. What is at issue? What should the content be?

2. What other relevant evidence might there be?

3. How else might one make sense of the data?

4. How were the data obtained?

In the role of participants as observers, the researchers revealed their role as researchers including what the aims and objectives of the research were. The researchers were particularly interested to gain the trust of the community of practice to arrive at valid and reliable research data. Making their identity as researchers clear it enabled the researchers to ask questions of their subjects to enhance their understanding.

The findings from each of the research methods such as literature review and face to face interviews were based on the strength of delete: the evidence from the interpretation and analysis of this data from each of the research methods, thus making incremental contributions towards answering the main research questions. The three research methods of literature review, face to face interviews and focus group meetings allowed the researchers to triangulate the newly collected data from these to validate the researchers' interpretations of the outcomes. This data tested the conclusions that the researchers drew from the literature review by testing the theory from the literature review against this new data, drawn from contemporary practice.

\section{Data Analysis and Representation}

It is important in research to defend the methods the researchers have chosen to conduct the research. The primary reason for this in the current research is to demonstrate that both academics and practitioners can have confidence that the researchers have produced data that is true to its context. The researchers demonstrated that they gained the trust of the participants in the face to face interviews and focus group meeting, by applying structured and consistent 


\section{Macrothink}

approaches to elicit empirical data to answer the main research questions. The researchers ensured that the level of reliability and validity increased in proportion to the research approaches applied.

The researchers considered that it would be most appropriate to review first what was already known about the subject matter and also to draw on other related research data from other studies. The community of practice (local community in Santiago de Cuba) also provided relevant research data based on their practical experiences. According to Kvale (1996), if social researchers want to know how people understand their world and their life, why not talk with them? In an interview conversation, the researcher listens to what people themselves tell about their lived world, hears them express their views and opinions in their own words, learns about their views on their work situation and family life, their dreams and hopes. The qualitative research interviews of this research attempted to understand the world from the subject's point of view, unfold the meaning of people's experiences and uncover their lived world prior to scientific explanation. The qualitative research interviews of this research were a construction site of knowledge. In this context, all interviews were literally 'inter views' between two or more persons conversing about a theme of mutual interest.

The authors of this research report made valuable contributions to the collection, management and interpretation of the research data from the community of practice by acting as participant observers, drawing on many years of practical experience of carrying out research. Fig.3 illustrates the research design process in diagrammatical form. 


\section{Ml Macrothink}

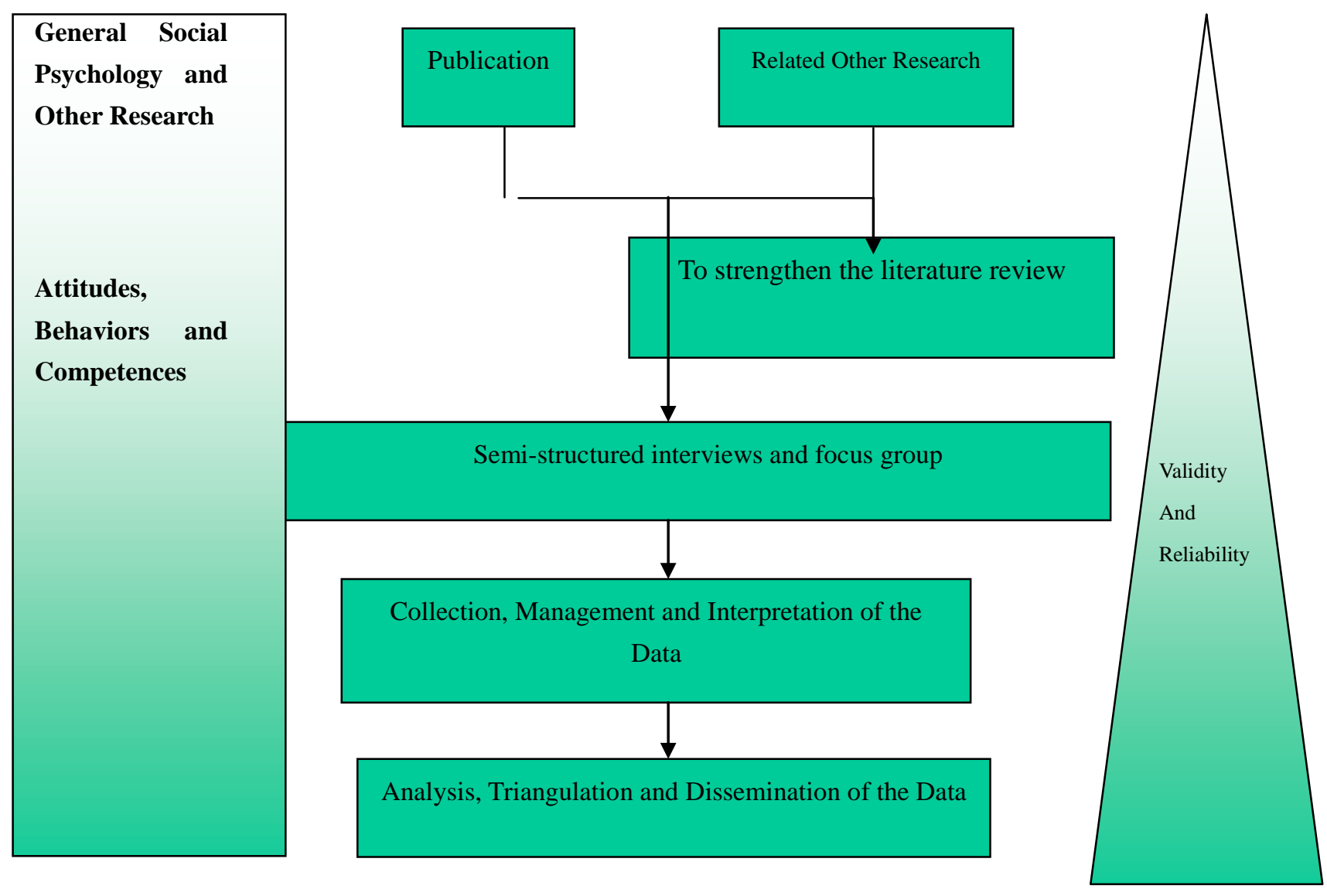

\section{Literature}

Empirical Material

Figure 3. Research Design Process Diagram (adapted from Blackburn, 2001)

Team 1 addressed the following issue: 'How to make better use of Free Time within the Community' to allow particularly the young people to do something constructively with their non-working time. Young people raised concern about the lack of facilities available to relax and have a good time. Team 2 managed the issue of 'How to improve the relationship between leaders of the community and its member. Team 3 had the challenge of 'Improving communications within the local community and motivate people to engage more in community activities'. Team 4 dealt with the issue of 'Men not doing enough work at home'.

Students faced two issues: 1 How to influence the leadership of the community to do something about this and improve the situation 2 To engage and motivate both young and older people to take ownership of these issues and work on solutions more proactively themselves.

The students applied a number of approaches to make the participants feel relaxed so they stayed focused throughout the sessions: a warm-up exercise to create interest, low key discussions to take this further to elicit more information from the participants and group exercises to create feelings of 'how things could be', using the creativity of the participants. Students also looked at the relationship between the young people and their communities.

This provided further insights into the some of the root causes of the problems the young people raised. Students motivated the participants to view things from different perspectives 
such as 'what is important to others'.

Participants began to see the value of why they should change their attitude towards the needs of the young people. They encouraged members of the community to influence the leaders of the community with a view to make the desired changes for the benefit of the young people and the community as a whole. Students promoted a series of activities such as 'playing games' that ultimately led to members of the community to take ownership of resolving social issues by themselves. They worked 'united' with the community to realize the desired changes.

Students generated repeat behaviors in people so they would no longer be afraid to engage in community issues and not wait for someone else to start the initiative. They created a sense of group belonging and being part of a team. The main objective of the research was to engage leaders and members of the local communities to provide them with the tools and techniques to become self-sufficient to deal with and manage issues they have. Students made participants aware of the positive outputs communities can achieve when they work together such as inspiring each other through interpersonal relationships and by being co-operative with each other to help.

Table 1 is a summary of analyzed data from the face to face interviews and focus group meetings that covers the work of the students, what value the work has added to people's own social lives, what members of the community would like to see done more or different and what should be done outside of Santiago de Cuba.

Table 1. Research Data Analysis

\begin{tabular}{|l|l|}
\hline 1 The Work of the Students: & 2 The Value added to own Social Live: \\
\hline $\begin{array}{l}\text { Excellent work, students care about the } \\
\text { communities and this encourages us. I am }\end{array}$ & $\begin{array}{l}\text { Has motivated me to do more and not give up } \\
\text { when things are difficult. Has made me more }\end{array}$ \\
happy. They have woken me up and others & aware of the social life within our \\
and made us think about our responsibilities & community. It has given me some new \\
and that we need to be committed to do & perspectives on what community life is all \\
something different to improve things. The & about. I have started to look at problems from \\
students have not only shown a great interest & a different point of view and this is helping \\
in finding solutions to our social issues but & me to engage more actively and try to resolve \\
they have also shown that they really care & issues proactively. New knowledge is applied \\
about helping us. Students did a good job. We & to our social life and this is a good thing. I \\
are all talking more in our communities as a & feel more comfortable now to look at my \\
direct result. The students have shown us the & own social life and feel more confident to \\
way forward and how we ourselves can make & implement positive improvements. The work \\
a difference to our daily social lives. I liked & of the students has motivated me to change \\
the different approach the students took to & my own behaviors to more positive and \\
develop solutions to our problems. The & forward-looking behaviors. The work of the \\
students have made us think more about the & students has made me think more about \\
things we did not worry about before but & things that are harmful to us and to think \\
which are important to us. The students have & more about what can be done to improve the \\
helped us a lot to see things differently. The & situation. Those who attended sessions have
\end{tabular}


students have been good listeners and shown a lot of sympathy for the problems of the local communities.

3 What should be done More Of/Differently:

Work more with specific groups of people such as the young or the workers. Help to resolve more material resource issues. We need to do more work in local communities to improve their ways of life and to resolve some social issues. Timings need to be better to ensure we can achieve higher qualities of outcome. There should be more activities like these as the students have already taught us important and interesting things. The students have shown us the way forward and given us some of the tools how to improve our social lives. Students should engage in more community work to ensure that our communities do not lose their social life values. We need to schedule any work in such a time that we can all make more contributions. Integrate people more to get involved. Hold meetings in places other than where the social problems are. Produce a documentary about the work the students have done, for broadcasting by Cuban TV.

\section{Negative Feedback:}

Some members of local communities in Santiago have indicated that they will not engage in any community work as they fell that a lot is talked about but that not much gets done. For example, houses are not repaired due to lack of materials being provided, drainage issues are not being resolved, pipes are broken but do not get repaired and garbage is not collected quick enough. Many members of the local communities only think about themselves and do not really care about others. Other communities would probably not benefit from further work as more robberies and changed how they think about social issues. The students have encouraged me to be bold and to engage in activities to resolve social issues within my communities.

4. What should be done Elsewhere in Cuba:

The knowledge and experience gained from this work in Santiago would definitely benefit other communities across Cuba. The UO approach of helping local communities should be rolled out to other parts of Cuba. All this work is developmental and should never stop. Others would learn a lot from some of the changes that have already been made as a direct result of all the community work. This work should also encourage other communities to find their own solutions to their problems but with the help and support from the UO. What is good for us here in Santiago will be of value and benefit to other communities across Cuba. Other communities would benefit in that it will make them also think about how to resolve their social issues. We have achieved a lot with the help and support of the UO and this should be rolled out to other communities. Students at other Universities should do something similar for their local communities.

6 Summary of Analysis:

The feedback sample size was 76 people. They indicated that they rated the overall work of the UO at a score of 8.76 out of 10 , with 10 being the highest positive score. In terms of being community-oriented, supportive and showing social care, the same sample size rated the UO at 8.82. As a direct result of the students' work with the local communities, $66 \%$ of research participants indicated that they are going to do a lot more community work in future. $25 \%$ indicated that they are going to do some more community work and 10\% indicated that they will not do any community work. These $10 \%$ 
much more corruption are happening now. Not so much talking is needed-a lot more of the doing is required. I do not think that the UO can make any difference as promises made to us are not kept but these may be outside the control of the UO. The support is meant well but we also need the resources such as materials. Many people do not believe in the meetings with students-they are a waste of time. Students are full of good and educated words but they cannot and do not make any difference-we need a roof over our heads, we need our streets repaired and we need sufficient food. The UO is not really interested in what goes on around here. A lot of propaganda but no action. More follow-up actions are needed.

\section{Results and Discussion}

The research participants from the local communities involved in this research placed a high importance on the work done by the students and the UO. They considered that it is important to apply the theoretical knowledge that is developed at the UO in a practical way for the benefits of members of local communities. They suggested that more should be done as it appears that the research work during the summer of 2012 was highly appropriate and successful. The delete: high majority of participants stated that they will get more involved in resolving problems within their communities in future. They no longer feel that they do not wish to get involved but feel more inspired and motivated to do something proactive and useful to make a contribution for the benefit of others. Members of the local communities no longer feel that they cannot resolve social issues by themselves. The students have 'awakened' a new awareness within people that they can actually resolve some social issues by focusing on working together within their communities. People have learned new skills with the help of the students and how to identify, address and manage community problems by applying new tools and techniques in a practical way.

It appears that communications and how people in communities talk to each other showed potential areas for improvement. This gap has now been closed by the work of the students and the UO. Students have worked closely with people and shown them through practical exercises how to improve communications and what the benefits are for doing so. People have learned that it is important to, first of all, listen a lot more than talk to gain a better understanding and feeling for how others perceive things. By showing sympathy and empathy, people can then engage more with others to try and resolve social problems more effectively. This is an effective approach as it can lead to much closer positive relationships between people through building trust between them. The following are excerpts from questionnaires that students completed with participants after the work was completed. 
'I sit down and I am hopeful when I see that university students worry about the social problems within my community'. This gives me great comfort. This is an indicator that things could change for the better. I believe that if this improves our community spirit, then it will also improve my own social life and that of my neighbors. We all need to work together to make this work' (Interview 1).'I am content. They have woken us up, myself and my neighbors and reminded us that taking responsibility and having commitment are two important ingredients of successful communities. Their meetings with us have provoked changes in behavior of some members of our community who did not really care too much about our community' (Interview 2). 'The work that the students have done for the community has been quite good, I feel well about this and it pleases me that the university dedicates time to us. The students have helped us to think about more what is important to us and our community and they have shown us the way to resolve some of these problems ourselves rather than wait for others to do it. They have shown us that we must also make time for our families and children. I can see things more clearly now and I am no longer afraid to address social issues and to something to put things right' (Interview 15).

'The work of the students has been very good. The students worked very hard to help our local community and their approach of working with us was very effective, too. Because of the work the students have done, there is now more dynamism, and a higher level of participation in social activities that concern our community. Relationships between community members have improved and my own social life has benefited, too' (Interview 32). 'The work carried out by the students has been excellent. They have demonstrated a high interest in our community. I am now looking at problems from different perspectives, taking into account how others think and fell. This has made a substantial difference to my social relationships with other members of the community' (Interview 55). 'I feel well with regard to the work that the students have carried out here in our communities. It has been good for us to improve our relationships within our own community and outside with other local communities. We now communicate more openly with each other. We have all learned how to relate better to other people and to ourselves' (Interview 62). 'I feel well. At the beginning, we did not really understand much of what they were doing. But soon we understood much more and the reasons why once the students explained everything to us.

We began to realize that nobody needs to be on their own to resolve issues and those we should concentrate on the things that we can change or improve ourselves. We also realized that it is important to engage everyone within the community to be involved in the discussions and work to resolve our social issues. This is good for our society' (Interview 65).'The most important thing in life is to have people around you who are willing to help because they want to. The students from the UO have been very good to us and have done a lot of good work for us to help us move things forward' (Interview 71). The main research questions from Section 1.2 of this research report have been answered (see Sections 3, 4 and 5).

\section{Conclusions}

Considering all the challenges that social psychologists are facing it is evident from the outcome of this research that there is one area where social psychology still needs to make big 
improvements: to bring theory and practice much closer together. The Faculty of Social Sciences of the Universidad de Oriente in Santiago de Cuba has already taken some major steps towards closing this gap.

A group of very enthusiastic and proactive students from the UO has taken the initiative to apply theoretical knowledge in areas such as attitude, behavior and competence to support and help local communities in Santiago de Cuba to resolve social issues and therefore improve their social lives. This is of paramount importance. Members of the communities, by their own admission, agreed that they had become complacent to do anything to improve their social well-being. Following interactions and interventions by the students, they now feel far more motivated and inspired to own their own social issues and to do something to resolve these issues and not wait for others to do this for them.

There has also been a considerable increase in improving effective communications within these communities and the UO feels confident that more improvements will be achieved in future as more work is planned in local communities based on the outcome of this research. Delete: work This work can be rolled out to other parts and cities across Cuba and it is considered that similar positive and effective results will be achieved for the benefit of local communities.

The outcome of this research confirms that students, under the supervision of professional teachers of the Faculty of Social Sciences, have made major contributions to local communities in Santiago de Cuba. They have carried out some investigative and intervention work to provide local communities with tools to become more self-sufficient to resolve social issues and not solely rely on the Government to do so. Their work corresponds closely to the expectations of the Cuban Social System in that the Universities in Cuba have moral obligations to help people in need.

This research was limited to working with local communities within the city limits of Santiago de Cuba. Further research in other communities across Cuba should be conducted to verify and validate the outcome of this research. This research was based on logical relationships and not just what, for example, people believe in. This research was delete: not be based on a positivist research paradigm The use of directly observed and experienced empirical research data from practitioners were fundamental for this research to answer the main research questions and within the ontological and epistemological positions of the researchers that the world is socially-constructed and that human beings make up things as they go along and that all experiences and knowledge, therefore, exist within this constructed world. The literature review of relevant publications was primarily based on more recent work to give this research some contemporary value. Publications after the year 2000 were of particular interest.

\section{Acknowledgement}

Special thanks to the Dean of the Faculty of Social Sciences at the Universidad de Oriente, Dra. Rosa Maria Reyes Bravo, for her continued help and support to enable us to carry out this research during 2012 within local communities of Santiago de Cuba. 


\section{Mll Macrothink}

Business and Economic Research ISSN 2162-4860 2013, Vol. 3, No. 1

We acknowledge the continuous excellent efforts of both academic staff and students of the Faculty of Social Sciences at the Universidad de Oriente who helped us in the successful execution of this research. Without their dedication and hard work we could not have achieved our research goals and objectives. .

\section{References}

Allport, G. W. (1935). In C. Murchison (Ed.). Handbook of social psychology, Worcester: Clark University Press, pages 798-844

Ajzen, I. (2005).Attitudes, Personality and Behavior, Second Edition, Open University Press, Mc Graw-Hill Education

Blackburn, S. (2001). Understanding Project Managers At Work, Henley Management College/Brunel University, DBA Thesis

Bromley, D. B. (1986). The Case Study Methodology in Psychology and Related Disciplines, Chichester: Wiley

Buunk, A. P. \& Van Vugt, M. (2008). Applying Social Psychology-From Problems to Solutions, Sage Publications Ltd.

Davenport, T. H. (1999). Human capital, Management Review, 88(11), pages 37-42

Fishbein, M. \& Ajzen, L. (1975). Belief, attitude, intention and behavior, Reading, MA: Addison-Wesley

Glaser, B. G., \& Strauss, A. L. (1967). The Discovery of Grounded Theory: Strategies for Qualitative Research, Chicago, Aldine Publishing Company

Hewstone, M., Stroebe, W. \& Jonas, K. (2008). Introduction to Social Psychology-A European Perspective, Fourth Edition, BPS Blackwell

Hodgetts, D., Drew, N., Sonn, C., Stolte, O., Nikora, L. W. \& Curtis, C. (2010). Social Psychology and Everyday Life, Palgrave Macmillan

Ivancevich, J. M. \& Matteson, M. T. (1992). Organizational Behavior and Management, Third Edition, Irwin

Katz, D. (1960). The fundamental approach to the study of attitudes, Public Opinion Quarterly, 24, 163-204. http://dx.doi.org/10.1086/266945

Kiesler, C. A., Collins, B. E. \& Miller, N. (1969). Attitude Change, New York: Wiley

Kvale, S. (1996). InterViews-An Introduction to Qualitative Research Interviewing, Sage Publications

La Piere, R. T. (1934). Attitudes versus Action, Social Forces, 13, 230-7. http://dx.doi.org/10.2307/2570339

Latour, B. (1987).Science in Action, Harvard University Press, Cambridge MA 


\section{Macrothink}

Business and Economic Research ISSN 2162-4860 2013, Vol. 3, No. 1

Lewin, K. (1951). Field theory in social science, New York: Harper \& Row

Lewin, K. (1946, 1948). Action research and minority problems. In G.W. Lewin (Ed.), Revolving Social Conflicts, pp.201-216, New York: Harper \& Row

Maio, G. R. \& Haddock, G. (2010). The Psychology of Attitudes and Attitude Change, Sage Publications Ltd.

Marshall, C. \& Rossman, G. (1995). Designing Qualitative Research, Second Edition, pages 22-25, Thousand Oaks, CA: Sage

Maxwell, J. A. (1996). Qualitative Research Design-An Interactive Approach, Volume 41, Applied Social Research Methods Series, Sage Publications,

Moore, D. R, Cheng, M.-I. \& Dainty, A. R. J. (2002). Competence, competency and competencies: performance assessment in organisations, Work Study: A Journal of Productivity Science, 51(6), 314-319

Playdon, Z. J. (2000). The Fairfield Centre: A Case Study in Democratic Management DBA thesis Henley Management College, Brunel University

Reber, A. S. (1995). Dictionary of Psychology, Penguin Books

Skinner, B. F. (1974). About Behaviorism, Jonathan Cape Ltd., London

Strauss, A. (1987). Qualitative analysis for social scientists, pages 48-56 Cambridge: Cambridge University Press http://dx.doi.org/10.1017/CBO9780511557842

Tajfel, H. (1981). Human Groups and Social Categories, Cambridge: Cambridge University Press

\section{Appendices}

\section{Appendix 1: Research Notes and Research Questionnaire for Students}

\section{Introduction and Background to the Study}

The Faculty of Social Sciences at the Universidad de Oriente has been a centre of excellence for social sciences research for many years. The faculty and its work is well-known and respected throughout Cuba. The University wishes to raise its profile and recognition in the area of social sciences and has therefore decided to conduct more research in the form of research programs to achieve wider local and international acclaims for its future work.

It appears that there is a growing need for social sciences to support local communities in Santiago de Cuba on a much wider and more in depth scale. The University has recognized this shortfall and now wishes to engage proactively in helping communities to benefit from the work of the faculty of social sciences. Theory is important but on its own is not as effective as theory and practice put together. It is the purpose of this research to combine theory and practice for the benefit of local communities in Santiago de Cuba. Depending on funds and 
other resources it is possible that this work will be rolled out in future to other cities and areas in Cuba.

This study will report on the outcomes of a literature review for social sciences to confirm whether the stated shortfall exists and how to develop the means to fill this shortfall. Publications from a number of countries will be considered for this purpose. The researchers acknowledge that what works well in one country, does not necessarily work equally well in another country.

Another objective of this research is to increase the levels of pro-social (proactive social) behavior of members of the local communities and measure these 6 months after the completion of this research. In this context, pro-social (proactive social) behavior is defined as helping someone without being asked to do so and that this work is not driven by companies, for example, who wish to make money out of this situation. The only exception is registered charities that usually have a desire to help others free of charge.

This research will assess psychological constructs such as attitude, behavior and competence. In the context of this research these are defined as follows:

"Attitude is a mental state of readiness, learned and organized through experience, exerting a specific influence on a person's response to people, objects, and situations with which it is related. Attitudes are determinants of behavior because they are linked to perception, personality and motivation" (Ivancevich and Matteson, 1992).

"Behavior is a generic term covering acts, activities, responses, reactions, movements, processes and operations, in other words, any measurable response of an organism"(Reber, 1995)

"Competence refers to areas of work at which the person is competent, the so-called areas for competence. The dimensions of behavior that underpin a competent performance are referred to as person-related" (Moore, Cheng and Dainty, 2002)

Attitudes, behaviors and competences people can actually observe, alone or with others, and where they can see the effects the applications of these have on other people, must be of greater value than being able to only experience these in the mind (positivist research approach). The researchers will apply a constructivist interpretivist approach within a phenomenological research paradigm so they can make a valid and reliable contribution to knowledge that is of value to both academics and practitioners.

\section{Leaving the Comfort of the Laboratory: Problems and Prospects}

Social psychologists often conduct research in real life situations, outside the controlled confines of the laboratory (or controlled and safe study environment). This can bring some difficulties with it. The predictability of the controlled environment is lost. Research in the real world is less predictable. Some typical examples are:

-no controlled manipulation of an independent variable

-no sensitive dependent variables that allow researchers to directly link cause with effect 
-no opportunity to debrief research participants

On the positive side, it is possible to capitalize on this:

-thinking broadly and creatively about social behavior in actual social contexts

-testing out ideas uncovered in the laboratory out in the field and vice versa

-using social psychological theory to explain or improve some practical issue in the social world

\section{Observational Research}

The most basic form of non-experimental social research involves simply looking around and observing what people do. This also includes capturing what people are saying, particularly observing their reactions to any research questions. Observational research does also normally not interfere in the situation-there is no intervention that might disrupt what is occurring naturally. Most observations are made in an unobtrusive or even 'secret' manner so that the individual(s) being observed do not alter their actions or change their replies deliberately.

\section{General Interview/Study Preparation Notes: Semi-structured Interviews}

Good planning and preparation are key components of any good and effective research. The following list is not exhaustive and you may find other points you wish to take into account before starting any field work:

a.) Tell the participants in the interviews that all information will be kept in total confidence and will only be used for conducting the research and any resulting actions to resolve stated issues and problems

b.) Inform participants that you will take all notes as you go along to capture what his being said. This will mean, from time to time, that you will not have eye contact with the participants

c.) Outline the purpose of the research, what will be done and how it will be done and what the desired outcome is

d.) Tell the participants what their roles are within the research and how they can help to make this successful. Motivate them to participate and encourage them at all times to do so

e.) Complete the accompanying research questionnaire as accurate as you can. Report only what is being said and not your own interpretations. There is no reason why you cannot capture your own notes/thinking as you go along but make sure this is clearly identified in the text so you do not mix the two different transcripts

f.) Write up the research report with all the captured Data within five days of the research while things are still fresh in the mind. Include your own thoughts and thinking in this report but make clear in the text what is yours! 


\section{Ml Macrothink}

Business and Economic Research ISSN 2162-4860 2013, Vol. 3, No. 1

g.) If you have access to a tape recorder, use it but tell the participants that you are doing this, and ask them if they feel comfortable for you to do this!

h.) Inform the participants that there will be a follow-up interview six months after the initial interview to get some further feedback on what has or has not happened

i.) To make you feel comfortable to carry out the research, do a pilot test. Ask a couple of fellow students to act as 'participants' and test how you are doing. Practice makes perfect!

j.) Use humor in the interviews to put people at ease but be careful not to overdo this

k.) We are going to use open ended questions in this research to make sure that people respond with sufficient details and not simply 'Yes' or 'No'. Repeat or reword the questions if people are not sure what the question means. Clarify where necessary. You may also have to probe for more information as some people will only give you the minimum. Use your own value judgment. But try to get as much information from people as possible. If people divert too much, bring them back on the right track but politely and with respect. Question 7 uses the Likert Scale approach (good practice).

1.) And ask any additional but relevant questions that might come to mind during the study. The more information we capture the better the quality of the research!

m.) Keep emotions out of the research and concentrate on the issues and concerns that people have. But, of course, show sympathy and empathy when necessary!

\section{Questions to Ask the Research Participants from the Local Communities}

1. How do you feel about the work the students have done for you? Why do you feel this way? Give examples.

2. What value has this work added to your social life? Explain your reasons.

3. Based on your personal experience, what do you suggest could/should be done more or differently/or less? Why is this so, what are your reasons for saying this?

4. How do you rate the overall work that the Universidad de Oriente (Faculty of Social Sciences) on a scale from 0 (very bad) to 10 (extremely good)? Why have you given this rating? Explain your reasons.

5. How do you rate the University in terms of:

\section{-Support}

-Social Care

-Being community-oriented

Again, from a scale of 0 to 10 and explain why you have given your ratings.

6. How would other communities across Cuba benefit from your experiences with the UO? Why is this so? 


\section{Macrothink \\ Business and Economic Research \\ ISSN 2162-4860 2013, Vol. 3, No. 1}

7. As a result of your experience, are you likely to:

a. to do a lot more work for the local community(becoming prosocial)?

b. to do some work for the local community

c. not care either way

d. not do much work for the local community

e. not do any work for the local community

Use the following ratings for each question above:

1. Strongly Agree

2. Disagree

3. Neither agree/disagree

4. Agree

5. Strongly Agree

Appendix 2: Research Team

\section{Research Programme Structure}

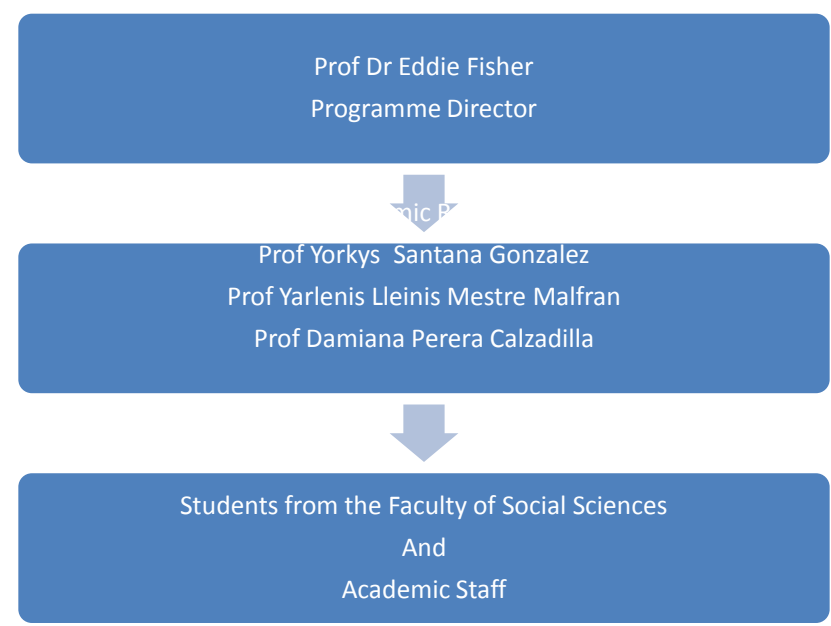

\section{Appendix 3: Seven Stages of the Interview Investigation}

1.Thematise: Formulate the purpose of an investigation and describe the topic to be investigated

2.Designing: plan the design of the study 


\section{Macrothink \\ Business and Economic Research \\ ISSN 2162-4860 2013, Vol. 3, No. 1}

3. Interviewing: conduct the interviews based on an interview guide

4. Transcribing: oral speech to written text, prepare interview material for analysis

5. Analysing: decide which methods are going to be used for this study or research

6.Verifying: ascertain the generalisability, reliability and validity of the research findings

7.Reporting: communicate the findings of the study or research and the methods applied in a form that lives up to scientific criteria

\section{Appendix 4: Qualification Criteria for Interviewers}
a.)Knowledgeable
b.)Structuring
c.)Clear
d.)Gentle
e.)Sensitive
f.)Open
g.)Steering
h.)Critical
i.)Remembering
j.)Interpreting

\section{Copyright Disclaimer}

Copyright reserved by the author(s).

This article is an open-access article distributed under the terms and conditions of the Creative Commons Attribution license (http://creativecommons.org/licenses/by/3.0/). 